\title{
0 senso comum e a vida cotidiana
}

\author{
JOSÉ DE SOUZA MARTINS
}

RESUMO: A História bloqueada pelo capital e pelo poder fez da vida cotidiana o refúgio para o desencanto de um futuro improvável. Os grandes embates pela redenção do gênero humano de suas limitações e misérias estão sendo readaptados a esse novo território da vida e do viver. A sociedade está sendo reinventada e, conseqüentemente, a sociologia também está passando por um processo de reinvenção. É nesse âmbito que ganha uma nova relevância a mediação do conhecimento do dia-a-dia na construção das relações sociais.

UNITERIMOS: vida cotidiana, conhecimento de senso comum, sociologia da vida cotidiana, sociologia do conhecimento

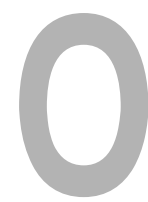

interesse sociológico pela vida cotidiana tem resultado diretamente do refluxo das esperanças da humanidade num mundo novo de justiça, de liberdade e de igualdade. Parece simples, mas é assim mesmo que a progressiva constituição da vida cotidiana como objeto de conhecimento da sociologia tem sido justificada.

De certo modo, há nessas origens uma descrença na História, uma renúncia à idéia de que o homem é senhor de sua História, de que pode produzir o seu próprio destino. O interesse pela vida cotidiana se difunde como um dos componentes mais nítidos do ceticismo decorrente das desilusões que tem acompanhado a notável capacidade de auto-regeneração da sociedade capitalista.

Para muitos, a vida cotidiana se tornou um refúgio para o desencanto de um futuro improvável, de uma História bloqueada pelo capital e pelo poder. Viver o presente já é uma consigna que encontra eco numa sociologia do detalhe, do aqui e hoje, do viver intensamente o minuto desprovido de sentido, que poderia ser definida como sociologia pós-moderna ${ }^{1}$. Ou, então, que poderia si- 
Essa concepção ganha sua expressão sociológica mais esclarecedora na obra de Michel Maffesoli. Entre outros livros desse autor, cf. Maffesoli (1983; 1988). Embora se apresente como um crítico da obra de Henri Lefebvre, Maffesoli dela se apropria, embora nem sempre com citações, "desistorizando-a", fazendo uma leitura compreensiva e anti-histórica de noções e perspectivas produzidas por uma interpretação dialética do viver, da vida cotidiana e da cotidianidade.

2 Cf. Schutz \& Luckmann (1977); Schutz (1972; 1974). Agradeço a José Jeremias de Oliveira Filho, que em meados dos anos 70 me pôs em contacto com a obra criativa e fascinante de Schutz e sua leitura singular da sociologia compreensiva. tuar a sociologia como uma das poderosas expressões da modernidade.

Esse refluxo tem tido muitas implicações no conhecimento sociológico. Viabilizou uma redescoberta das sociologias fenomenológicas, sugeriu uma crítica nova ou renovada à sociologia positivista, abriu um amplo campo de investigações teóricas. De certo modo, estamos diante de um fascinante processo de reinvenção da sociedade. Mas também de reinvenção da sociologia.

Se a sociologia do século XIX e da primeira metade deste século descobriu o homem como criatura da sociedade, o período recente põe a sociologia ante a crise dessa concepção e crise dessa verdade relativa e transitória. Porque, no fundo, crise de uma sociedade dominada por grandes e definitivas certezas, a da ilimitada reprodução do capital e a da inesgotável força de coação do poder do Estado.

As grandes certezas terminaram. É que com elas entraram em crise as grandes estruturas da riqueza e do poder (e também os grandes esquemas teóricos). Daí decorrem os desafios deste nosso tempo. Os desafios da vida e os desafios da ciência, da renovação do pensamento sociológico.

Se a vida de todo o dia se tornou o refúgio dos céticos, tornou-se igualmente o ponto de referência das novas esperanças da sociedade. O novo herói da vida é o homem comum imerso no cotidiano. É que no pequeno mundo de todos os dias está também o tempo e o lugar da eficácia das vontades individuais, daquilo que faz a força da sociedade civil, dos movimentos sociais.

Nesse âmbito é que se propõe a questão do conhecimento de senso comum na vida cotidiana. Questão porque, na perspectiva erudita, o senso comum é desqualificado porque banal, destituído de verdade, fonte de equívocos e distorções. E com ele o mundo de que faz parte, o da vida cotidiana. Não era assim que pensava Émile Durkheim em As regras do método sociológico e também em Sociologia e filosofia? (cf. 1960; 1963)

Questão porque, se no refúgio da vida cotidiana o homem descobre a eficácia política (e Histórica) de sua aparente solidão, impõe, também, o reconhecimento de que o senso comum não é apenas instrumento das repetições e dos processos que imobilizam a vida de cada um e de todos.

Isso nos remete criticamente de volta a suposições fundamentais do pensamento sociológico. Do lado do positivismo, à revisão da idéia de que só o fato desprovido de vida é social. Crítica que, aliás, a sociologia fenomenológica de Alfred Schutz já fez de modo eficaz ${ }^{2}$. Do lado da dialética, à revisão da idéia de que só a conversão consciente ao projeto da revolução pode revolucionar a vida.

Em tudo, o questionamento de que um senso comum desprovido de sentido condena irremediavelmente o homem comum ao silêncio e à condição de vítima das circunstâncias da História.

A hipótese de que "os homens fazem a sua própria História, mas não a fazem como querem e sim sob as circunstâncias que encontram, legadas 
MARTINS, José de Souza. O senso comum e a vida cotidiana.Tempo Social; Rev. Sociol. USP, S. Paulo, 10(1): 1-8, maio de 1998.

e transmitidas pelo passado" (Marx, 1961, p. 203) retorna forte e desafiadora. Não só aos que querem mudar o mundo, mas também aos que querem compreender e explicar essa mudança. Esse desencontrado agir histórico pede e propõe uma reflexão propriamente sociológica ${ }^{3}$. E essa reflexão incide exatamente sobre as características, as peculiaridades e a eficácia desse conhecimento próprio da realidade de todo dia, até há pouco recusado ou desqualificado justamente em nome de seu suposto desencontro com a História. O que é mesmo fazer História sem saber que a estamos fazendo? A proposta que há nessa pergunta implica em passar da Filosofia à Sociologia e, mais concretamente, a uma sociologia da vida cotidiana.

A possibilidade de uma sociologia da vida cotidiana está nesse âmbito intermediário, na investigação e superação do que o senso comum tem sido para a interpretação acadêmica: ou apenas o conhecimento com que o homem comum define a vida cotidiana, dando-lhe realidade, como supõem Berger e Luckmann; ou apenas o conhecimento alienado da falsa consciência que separa o trabalhador do mundo que ele cria, de que nos falam os marxistas.

Em A questão judaica, Marx já havia mostrado que no desencontro do homem e daquilo que faz há também um encontro e um ato de criação histórica e social (cf. Marx, 1973). O mesmo se repete em outros textos desse autor.

É por isso que me proponho a desenvolver aqui uma breve reflexão sociológica que me permita encontrar na divergência de orientações teóricas de marxistas e fenomenologistas a possibilidade de um encontro justamente naquilo que, sob diversos nomes, é na verdade o lugar do conhecimento de senso comum na vida cotidiana e, também, na História.

Não me preocupa, neste momento, o desacordo essencial entre autores de um grupo e de outro. Nem me motiva o ecletismo ingênuo que poderia existir na tentativa de fundir sem critério, e sem crítica, as constatações de uns e de outros.

Há, sem dúvida, uma enorme riqueza de interpretações do senso comum nas sociologias fenomenológicas. Muito maior, certamente, do que a limitada concepção que do senso comum tinha Durkheim (e também Max Weber na sua tipologia da ação). É notório que nas recaídas positivistas da Sociologia haja sempre um empobrecimento de sua definição, como se vê em Berger e Luckmann: "a sociologia do conhecimento deve, sobretudo, ocuparse do que as pessoas 'conhecem' como 'realidade' na sua vida cotidiana..." (Berger \& Luckmann, 1968, p. 31). Apesar de discípulos de Schutz, eles colocam o conhecer, o senso comum, numa relação de exterioridade com o viver (a vida cotidiana). Essa coisificação do conhecimento de senso comum está em contradição com o lugar que ocupa na tradição fenomenológica.

O senso comum é comum não porque seja banal ou mero e exterior conhecimento. Mas porque é conhecimento compartilhado entre os sujeitos da relação social. Nela o significado a precede, pois é condição de seu esta-

Esse fundamental retorno sociológico à dialética está exposto de maneira completa e clara em Henri Lefebvre (1966). 
belecimento e ocorrência. Sem significado compartilhado não há interação. Além disso, não há possibilidade de que os participantes da interação se imponham significados, já que o significado é reciprocamente experimentado pelos sujeitos. A significação da ação é, de certo modo, negociada por eles. Em princípio, não há um significado prévio ou, melhor dizendo, não é necessário que haja significações preestabelecidas para que a interação se dê. Um aspecto essencial dessa formulação é o de que esse complicado jogo se desenrola, de fato, em minúsculas frações de tempo. Se nos fosse possível observar o processo interativo em "câmara lenta", poderíamos perceber o complexo movimento, o complicado vai-e-vem de imaginação, interpretação, reformulação, reinterpretação, e assim sucessivamente, que articula cada fragmentário momento da relação entre uma pessoa e outra e, mesmo, entre cada pessoa e o conjunto dos anônimos que constituem a base de referência da sociabilidade moderna.

Além disso, os significados que mediatizam os relacionamentos entre as pessoas estão sujeitos a um complexo mecanismo de deciframento. Os interacionistas simbólicos mostraram como a interação só é possível por meio de procedimentos interpretativos que fazem da relação social uma construção (cf. esp. Blumer, 1969).

Não há apenas negociação e interpretação de significados, mas também critérios para seu uso. A sociologia de Erving Goffman justamente demonstra que as relações sociais estão permeadas por uma dramática atividade de simulação e teatralização para que, afinal, o significado produzido e reconhecido na interação não acarrete o descrédito para o sujeito (cf. esp. Goffman, 1971). Isso quer dizer que o ator não se dirige imediata e diretamente ao outro para com ele interagir. A interação é precedida pela simulação, pelo exercício que o sujeito faz de experimentar-se como outro, numa relação de exterioridade consigo mesmo, nos segundos que constituem o preâmbulo do seu relacionamento. Uma imensa construção imaginária define a circunstância da relação social.

Por sua vez, a etnometodologia sugere que a interação não repousa nos significados que a mediatizam, simplesmente. O conhecimento cotidiano não é constituído apenas de significados. De fato, o que caracteriza o experimento etnometodológico é a utilização de catástrofes artificialmente produzidas como recurso para criar situações de anomia e destruir os significados que sustentam a interação. Os experimentos têm demonstrado que, com grande rapidez, os envolvidos na circunstância de privação repentina de significados são capazes de criar significados substitutivos e restabelecer as relações sociais interrompidas ou, mais que isso, ameaçadas de ruptura. Portanto, mais do que uma coleção de significados compartilhados, o senso comum decorre da partilha, entre atores, de um mesmo método de produção de significados (cf. Garfinkel, 1967). Portanto, os significados são reinventados continuamente ao invés de serem continuamente copiados. As situações de anomia e desordem são resolvidas pelo próprio homem comum justamente porque ele 
MARTINS, José de Souza. O senso comum e a vida cotidiana.Tempo Social; Rev. Sociol. USP, S. Paulo, 10(1): 1-8, maio de 1998.

dispõe de um meio para interpretar situações (e ações) sem sentido, podendo, em questão de segundos, remendar as fraturas da situação social.

As descobertas da etnometodologia sugerem que a desordem e a revolta só atingem a ordem superficialmente, pois apenas suprimem significados por um certo tempo, sem atingir o método (de senso comum), o critério, dos procedimentos que reconstituem o tecido rompido. Alvin W. Gouldner, mesmo em sua notória indisposição para com as descobertas de Garfinkel, observou acertadamente que a etnometodologia colocou a rebelião possível no lugar da revolução impossível (cf. Gouldner, 1972, p. 394). No fundo, são descobertas que detalham os sutis e complicados mecanismos do que os autores marxistas denominam reprodução social ${ }^{4}$.

Se outra importância não tivesse tal tipo de descoberta, serviria ao menos para demonstrar a dinâmica do imobilismo, do repetitivo, da permanência e do que muitos também chamam de vida cotidiana. E do profundo compromisso que as ciências sociais podem eventualmente ter com a negação da vida e da emancipação do homem de suas carências, em particular a carência de liberdade.

Na raiz da própria interpretação fenomenológica, porém, o conhecimento de senso comum e a vida cotidiana que ele viabiliza aparecem circunscritos ao âmbito da atenção e da vigília. O que, no fundo, sugere uma instabilidade permanente da vida cotidiana, sujeita aos choques que estabelecem descontinuidades mais ou menos profundas na passagem de um mundo a outro do que Schutz define como realidades múltiplas. Múltiplas, justamente, porque cada mundo (como a vida cotidiana, o sonho, a loucura etc.) tem o seu próprio estilo cognitivo, definidor dos limites de suas significações. Embora a vida cotidiana seja o mundo que dá sentido aos demais, enquanto referência, aparece subvertida e alterada nesses outros mundos. $\mathrm{O}$ que nos mostra as descontinuidades que atravessam a vida cotidiana todos os dias.

Essas descontinuidades também são constatadas pelas interpretações dialéticas. Ainda que de outro modo, não é delas que nos fala a teoria da alienação? Não é delas que nos fala Karel Kosik quando proclama a cisão da práxis (e da consciência) em práxis utilitária cotidiana e práxis revolucionária? (cf. Kosik, 1976).

Elas aparecem, porém, de modo mais rico nas interpretações de Ágnes Heller e de Henri Lefebvre. Mais neste do que naquela. Em ambos, nos momentos de elevação acima da cotidianidade; nos momentos superiores, criadores e privilegiados, em contraste com os instantes banais da vida cotidiana (cf. Périgord, 1977). Mesmo na rotina alienadora da fábrica e da produção há momentos de iluminação e criação (cf. Périgord, 1977, p. 236), de invasão do cotidiano e do senso comum pela realidade e pelo conhecimento que revolucionam o cotidiano.

O vivido em Schutz é o vivido dos significados que sustentam as relações sociais. Mas, em Lefebvre, o vivido é mais que isso: é a fonte das contradições que invadem a cotidianidade de tempos em tempos, nos mo-

Cf. a rica volta ao tema da reprodução proposta por Henri Lefebvre (1973). 
${ }^{5}$ Foi Henri Lefebvre quem propôs de maneira sociologicamente mais consistente a questão do possivel, articulando-a com o tema dos resídu$o s$, do que não pode ser capturado pelos poderes e, portanto, propõe e reclama o novo. Uma inovação essencial em sua obra é a indicação de que além de dedução e indução, a ciência social deve trabalhar com a transdução, a lógica do possível. Entre outros livros desse autor sobre esses temas, cf. Lefebvre (1958; 1957; 1965a; 1972).

${ }^{6}$ Cf. Heller (1978). O tema das necessidades radicais, as necessidades que fundam a práxis revolucionária ou inovadora, aparece proposto originalmente em Henri Lefebvre (1965b). mentos de criação.

A reprodução social, lembrou Lefebvre mais de uma vez, é reprodução ampliada de capital, mas é também reprodução ampliada de contradições sociais: não há reprodução de relações sociais sem uma certa produção de relações - não há repetição do velho sem uma certa criação do novo, mas não há produto sem obra, não há vida sem História. Esses momentos são momentos de anúncio do homem como criador e criatura de si mesmo.

É no fragmento de tempo do processo repetitivo produzido pelo desenvolvimento capitalista, o tempo da rotina, da repetição e do cotidiano, que essas contradições fazem saltar fora o momento da criação e de anúncio da História - o tempo do possível ${ }^{5}$. E que, justamente por se manifestar na própria vida cotidiana, parece impossível. Esse anúncio revela ao homem comum, na vida cotidiana, que é na prática que se instalam as condições de transformação do impossível em possível.

Heller disse que só quem tem necessidades radicais pode querer e fazer a transformação da vida ${ }^{6}$. Essas necessidades ganham sentido na falta de sentido da vida cotidiana. Só pode desejar o impossível aquele para quem a vida cotidiana se tornou insuportável, justamente porque essa vida já não pode ser manipulada.

É aí que o reencontro com as descobertas das orientações fenomenológicas ganha novo e diferente sentido. Pois, é no instante dessas rupturas do cotidiano, nos instantes da inviabilidade da reprodução, que se instaura o momento da invenção, da ousadia, do atrevimento, da transgressão. E aí a desordem é outra, como é outra a criação. Já não se trata de remendar as fraturas do mundo da vida, para recriá-lo. Mas de dar voz ao silêncio, de dar vida à História.
Recebido para publicação em janeiro/1998

MARTINS, José de Souza. Common sense and everyday life. Tempo Social; Rev. Sociol. USP, S. Paulo, 10(1): 1-8, may 1998.

ABSTRACT: History blocked by Capital and power has turned everyday life into a refuge from the disenchantment of an unlikely future. The big struggles in order to redeem humankind from its limits and miseries are being readapted to this new territory of life and living. Society is being reinvented, and consequently sociology is also experiencing a process of reinvention. In this context the mediation of knowlegde of the day-by-day gets a new importance in the construction of social relations. 


\section{REFERÊNCIASBIBLIOGRÁFICAS}

Berger, Peter \& Luckmann, Thomas. (1968) La construcción social de la realidad. Buenos Aires, Amorrortu Editores.

BLUMER, Herbert. (1969) Symbolic interactionism. New Jersey, Prentice-Hall, Inc. / Englewood Cliffs.

DuRKHEIM, Émile. (1960) As regras do método sociológico. Trad. Maria Isaura Pereira de Queiroz. São Paulo, Cia. Editora Nacional.

. (1963) Sociologie et philosophie. Paris, Presses Universitaires de France.

Garfinkel, Harold. (1967) Studies in ethnomethodology. New Jersey, Prentice-Hall, Inc. / Englewood Cliffs.

GoFFMAn, Erving. (1971) La presentación de la persona en la vida cotidiana. Buenos Aires, Amorrortu Editores.

GOULDNER, Alvin W. (1972) The coming crisis of western sociology. London, Heinemann.

Heller, Agnes. (1978) La théorie des besoins chez Marx. Paris, Union Générale d'Éditions.

Kosik, Karel. (1976) Dialética do concreto. Trad. Célia Neves e Alderico Toríbio. $2^{\text {a }}$ ed. Rio de Janeiro, Paz e Terra.

Lefebvre, Henri. (1957) La pensée de Lénine. Paris, Bordas.

. (1958) Critique de la vie quotidienne. Vol. I. $2^{\mathrm{a}}$ ed. Paris, L'Arche Éditeur.

. (1965a) Métaphilosophie. Paris, Les Éditions de Minuit.

. (1965b) La proclamation de la commune. Paris, Gallimard.

. (1966) Sociologie de Marx. Paris, Presses Universitaires de France.

. (1972) La revolución urbana. Trad. Mario Nolla. Madrid, Alianza Editorial.

. (1973) La survie du capitalisme (La re-production des rapports de production). Paris, Anthropos.

MafFesoli, Michel. (1983) La conquista del presente (Per una sociologia della vita quotidiana). Trad. Anna Grazia Farmeschi e Alfonso Almafitano. Roma, Editrice Ianua.

. (1988) O conhecimento comum (compêndio de sociologia compreensiva). Trad. Aluizio Ramos Trinta. São Paulo, Brasiliense.

MARX, Karl. (1961) O 18 Brumário de Luís Bonaparte. In: MARX, Karl \& ENGELs, F. Obras escolhidas. $2^{\mathrm{a}}$ ed. Rio de Janeiro, Editorial Vitória.

. (1973) La cuestión judía. In: MARX, Karl \& RugE, Arnold. Los anales franco alemanes. Barcelona, Martinez Roca. 
Périgord, Monique. (1977) Henri Lefebvre ou les moments de la quotidienneté. Revue de Synthése, 87-88:235-254, juillet-decembre.

Schutz, Alfred \& Luckmann, Thomas. (1977) La estruturas del mundo de la vida. Trad. Néstor Míguez. Buenos Aires, Amorrortu Editores.

SchUTz, Alfred. (1972) Fenomenología del mundo social (Introducción a la sociología compreensiva). Trad. Eduardo J. Prieto. Buenos Aires, Paidos.

. (1974) Estudios sobre teoría social. Trad. Néstor Míguez. Buenos Aires, Amorrortu Editores. 